\title{
An audit of cavity and crown preparations and two direct restorations carried out by foundation dentists in the Oxford and Wessex Deaneries
}

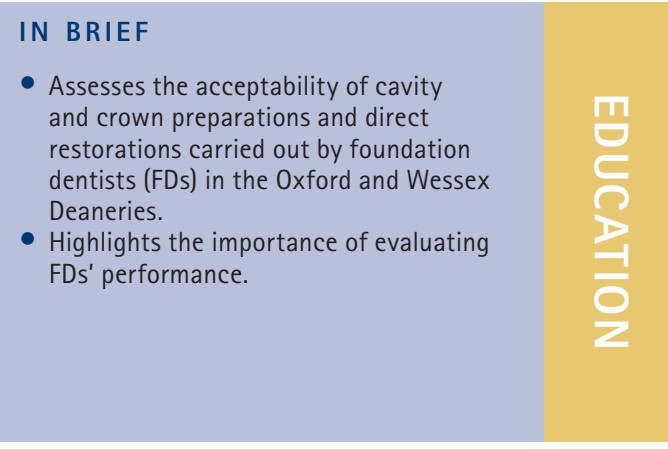

\author{
F. J. T. Burke, ${ }^{* 1}$ L. Mackenzie, ${ }^{2}$ H. Falcon, ${ }^{3}$ N. Priest ${ }^{3}$ and W. M. Palin ${ }^{4}$
}

It is likely that many foundation dentists (FDs) will have completed only minimal amounts of restorative dentistry for a number of months immediately prior to commencing work as FDs. Thus this audit aimed to assess the performance of the FDs when they carried out a number of simulated clinical exercises: amalgam cavities and restoration; Class IV resin composite restorations; and full crown preparations for metal-ceramic restorations. A total of 67 FDs completed the assessments and some results did indicate a high level of concern and need for further evaluation of restorative practice.

\section{INTRODUCTION}

The purpose of dental foundation training is defined in the NHS Performers List Regulations as a relevant period of employment during which a dental practitioner is employed under a contract of service by an approved trainer to provide a wide range of dental care and treatment. Also, to attend such study days as that contract provides, with the aims and objectives of enhancing clinical and administrative competence and promoting high standards through relevant postgraduate training that includes the following: ${ }^{1}$

- To enable the dental practitioner

to practise and improve the dental practitioner's skills

- To introduce the dental practitioner to all aspects of dental practice in primary care

- To identify the dental practitioner's personal strengths and weaknesses and balance them through a planned programme of training

- To promote oral health of, and quality dental care for, patients

- To develop and implement peer and selfreview, and promote awareness of the need for professional education, training and audit as a continuing process.

${ }^{1}$ Primary Dental Care Research Unit, ${ }^{2}$ School of Dentistry, ${ }^{4}$ Biomaterials, University of Birmingham, School of Medical and Dental Sciences, St. Chad's Queensway, Birmingham, B4 6NN; ${ }^{3}$ Oxford and Wessex Deaneries, The Triangle, Roosevelt Drive, Oxford, OX3 7XP

${ }^{*}$ Correspondence to: Prof Trevor Burke

Email: f.j.t.burke@bham.ac.uk; Tel: +44 1214665476

Refereed Paper

Accepted 19 December 2013

DOI: 10.1038/sj.bdj.2014.249

${ }^{\circledR}$ British Dental Journal 2014; 216: 421-425
Foundation dentists (FDs) are predominately recent graduates of UK dental schools, with training programmes being designed to meet the requirements of the UK dental foundation training curriculum. ${ }^{2}$ On completion of a year's training the dentist is awarded a foundation training certificate by a postgraduate dental dean or director, allowing the dentist to perform NHS primary care dental services without supervision.

Before graduation, the FDs will have completed a variable number of direct and indirect restorations, based on the curriculum set by their different universities of graduation, but also sufficient to satisfy the regulatory body, the UK General Dental Council (GDC). There is a likelihood that many FDs will have completed only minimal amounts of restorative dentistry for a number of months immediately before commencing work as FDs, given that their clinical activities during their final months at dental school may have been channelled into preparation for their final examinations, completion of so-called 'presentation cases', visiting practices, and, in addition, having a break of circa eight weeks after graduation. It was therefore considered desirable by the Oxford and Wessex Deaneries that the FDs should undertake a day-long basic restorative dentistry 'refresher course' on phantom head models as soon as possible after entering the dental foundation training programme. It was also suggested that their performance on this course should be externally reviewed, in order to inform a preliminary assessment of their individual learning needs, so that any areas identified for improvement could be targeted, working closely with their clinical and educational supervisors (trainers). It was further agreed that this activity should be subjected to an audit, across all five training schemes; ideally with the exercise being repeated before the end of the FD year to assess progress.

It is therefore the aim of this study to assess the performance of the FDs when they carried out a number of simulated clinical exercises.

\section{METHODS}

\section{The operative training exercise}

All preparations and restorations were carried out on standard plastic teeth (Kavo model teeth with numbered roots) mounted in a full arch in phantom heads, mounted either on a work bench or as part of a purpose built unit to simulate a normal clinical operating position.

\section{Amalgam cavities and restoration}

Having previously been shown a radiograph of a carious lesion that they have been asked to treat, the FDs were asked to prepare a distoocclusal Class II cavity in tooth 36, with the cavity size being appropriate to the radiograph that they had been shown and the cavity design being appropriate for an amalgam restoration. The FDs then were asked to repeat the exercise on the 46 and then use their 'normal' technique to restore the cavity with amalgam. They were only permitted to do this once.

\section{Class IV resin composite restorations}

Standardised Class IV cavities were pre-cut in tooth 21 and the margins of the cavity 
Table 1 Criteria for the assessment of the preparations/restorations carried out by the FDs

\begin{tabular}{|c|c|c|c|}
\hline $\begin{array}{l}\text { Key } \\
\text { Indirect }\end{array}$ & $\begin{array}{l}1 \\
\text { Optimal }\end{array}$ & $\begin{array}{l}2 \\
\text { Clinically acceptable }\end{array}$ & $\begin{array}{l}3 \\
\text { Unsatisfactory }\end{array}$ \\
\hline \multicolumn{4}{|l|}{ Occlusal surface } \\
\hline Contour & Pre-operative contour obvious & General features present & Loss of contour \\
\hline \multicolumn{4}{|l|}{ Margins } \\
\hline Chamfer & $\begin{array}{l}\text { Uniform } 0.5 \mathrm{~mm} \text { depth, follows gingival } \\
\text { contour }\end{array}$ & Some sub-optimal areas & Margins unacceptable for technician \\
\hline \multicolumn{4}{|l|}{ Axial surfaces } \\
\hline Reduction & $1.5 \mathrm{~mm}$ alloy + porcelain & Restoration could be made & $\begin{array}{l}\text { Insufficient room for materials/ } \\
\text { over-preparation }\end{array}$ \\
\hline Axial length & Optimum & Adequate retention form & Insufficient retention \\
\hline Convergence angles & Optimum 5-10 & Adequate $10-20^{\circ}$ & $>20 \%$ undercut \\
\hline Outline form & $\begin{array}{l}\text { Optimal Resistance form (conforms } \\
\text { to premolar outline) }\end{array}$ & Adequate resistance form & Loss of shape/poor resistance form \\
\hline Surface finish & All surfaces smooth/rounded line angles & Clinically acceptable & Poor finish/sharp line angles \\
\hline latrogenesis & Zero & $\begin{array}{l}\text { Minor damage (consistent with } \\
\text { hand instrument) }\end{array}$ & Bur damage \\
\hline Composite restoration & 1 & 2 & 3 \\
\hline Labial contour & Optimal & $\begin{array}{l}\text { Over or under } \\
\text { contoured }\end{array}$ & $\begin{array}{l}\text { Grossly over or under } \\
\text { contoured }\end{array}$ \\
\hline Incisal edge form & $\begin{array}{l}\text { Parallel to interpupillary line optimal thickness/ } \\
\text { position }\end{array}$ & Some errors & Unsatisfactory \\
\hline Proximal contour & Optimal & Sub-optimal & Concave or otherwise unsatisfactory \\
\hline Palatal contour & Optimal & Over or undercontoured & Grossly over or undercontoured \\
\hline Margins & Optimal & Minor excess & $\begin{array}{l}\text { +ve/-ve ledge } \\
\text { Rough or stained }\end{array}$ \\
\hline Voids/layers & None & Minor (will not affect longevity/aesthetics) & Major defects \\
\hline Surface finish & Optimal & Some rough areas & Rough generally subject to stain \\
\hline latrogenesis & None & $\begin{array}{l}\text { Minor (consistent with hand instrument/disc/ } \\
\text { finishing strip) }\end{array}$ & Bur damage \\
\hline Amalgam preparation & 1 & 2 & 3 \\
\hline \multicolumn{4}{|l|}{ Proximal box } \\
\hline Design & Optimal & Clinically acceptable & Unsatisfactory \\
\hline Depth & $\begin{array}{l}\text { Sufficient to remove caries/cervical contact } \\
\text { clear/ 3 } \mathrm{mm}\end{array}$ & Clinically acceptable & $\begin{array}{l}\text { Insufficient for lesion } \\
\text { Cervical contact remains }\end{array}$ \\
\hline Margins & Optimal & Sub-optimal & Fragile enamel/rough \\
\hline latrogenesis & None & Minor (hand instrument) & Bur damage \\
\hline \multicolumn{4}{|l|}{ Occlusal lock } \\
\hline Design & Optimal & Clinically acceptable & Unsatisfactory \\
\hline Depth & $1.5-2.0 \mathrm{~mm}$ & Clinically acceptable & $\begin{array}{l}\text { Over-preparation } \\
\text { Pulpal exposure insufficient space for amalgam }\end{array}$ \\
\hline Amalgam restoration & 1 & 2 & 3 \\
\hline Anatomical form & Optimal & Some errors & Unsatisfactory \\
\hline Contact point & $\begin{array}{l}\text { Optimal } \\
\text { Tight/natural contour }\end{array}$ & Sub-optimal & $\begin{array}{l}\text { Open } \\
\text { Food trap }\end{array}$ \\
\hline Marginal ridge height & $\begin{array}{l}\text { Optimal } \\
\text { Same as adjacent teeth }\end{array}$ & Clinically acceptable & $\begin{array}{l}\text { Too high } \\
\text { Fracture risk } \\
\text { Too low } \\
\text { Food trap } \\
\text { Weak }\end{array}$ \\
\hline
\end{tabular}


sandblasted with an intraoral sandblaster (Cojet: 3M ESPE, Seefeld, Germany). FDs were then asked to restore the cavity with resin composite, using a dentine bonding agent.

\section{Full crown preparations for metal-ceramic restorations}

FDs were asked to prepare two teeth for metal-ceramic crown preparations, 25 and 15. Before carrying out the preparations, each group of FDs was given a PowerPoint presentation (which had been prepared by one of the authors [LM]) in which they were given standardised instructions, including: the palatal margin aspect will be metal (no porcelain coverage) with a chamfer margin, the occlusal surface will have ceramic coverage, and the buccal surface will also have ceramic coverage. This was delivered by training programme directors or experienced trainers. The FDs were left to determine the shoulder thickness appropriate for the required materials. Additionally, it was suggested that the interproximal preparation would be a minimal shoulder. The instructions were based upon standard texts on crown preparation, such as Shillingburg. ${ }^{3}$ The FDs were left to judge the depth of the preparation as part of the exercise.

Before carrying out the preparations, the FDs were asked to make a polyvinylsiloxane putty index of each tooth before preparation. They were asked to carry out the 25 preparation first, and to do this preparation without the aid of the putty index. For the 15 preparation, FDs were asked to carry out the preparation and then use the sectioned index to gauge preparation depths and adjust in accordance with their undergraduate teaching.

\section{The audit}

A simple scoring system was devised by one of the authors (LM), based upon generally-considered criteria for an ideal amalgam Class II cavity, an anatomically satisfactory Class IV resin composite restoration and a satisfactory crown preparation (Table 1). When the FDs had completed their preparation and restoration exercises, the models were collected and sent to a central area (Winchester Postgraduate Centre) where two examiners (FJTB and LM) assessed the restorations using modified USPHS/Ryge criteria. ${ }^{4}$ These criteria typically include grades for colour match, cavo-surface discolouration, secondary caries, anatomic form and marginal adaptation. However, because of the need to use plastic models for which there will necessarily be a suboptimal shade match, neither shade match, caries or marginal discolouration could be assessed and, therefore, only anatomic form and

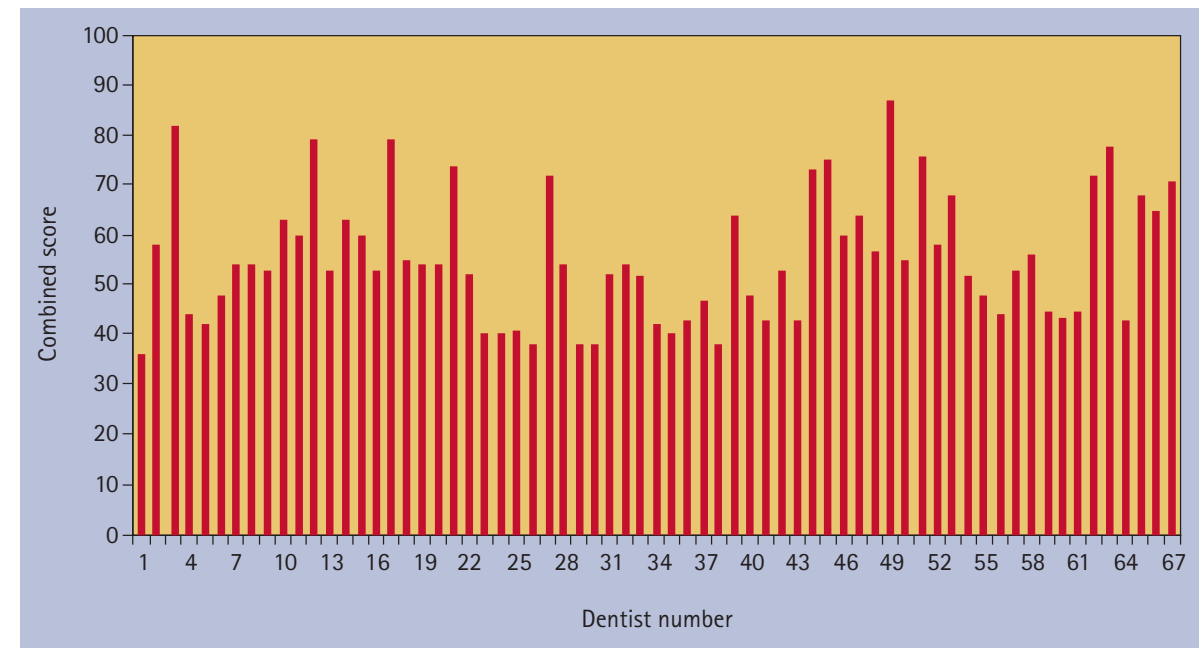

Fig. 1 Overall scores

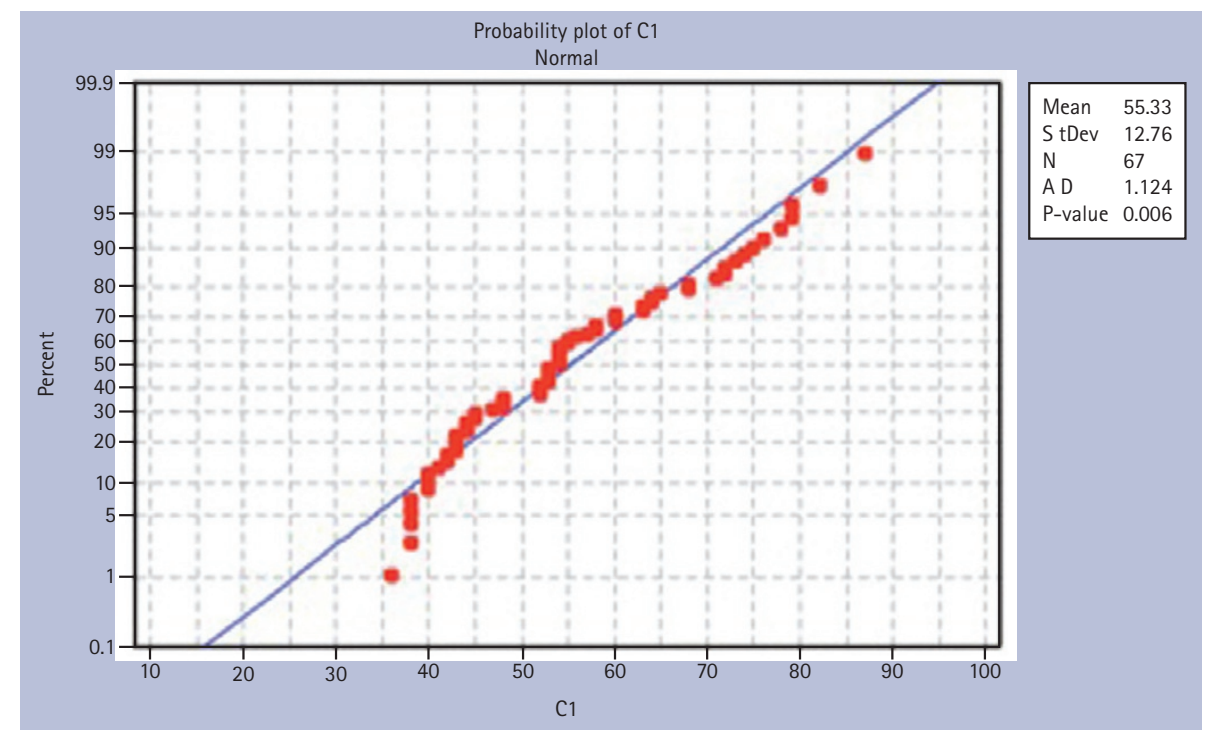

Fig. 2 The result of a Shapiro-Wilk normality test of the ordinal data obtained in the current investigation. A significant difference in the pattern of data was observed compared with that expected from a population with a normal distribution $(p<0.05)$

marginal adaptation were considered. Before carrying out this exercise, the FDs were given a short PowerPoint presentation on USPHS/ Ryge criteria so that they would be familiar with the assessment criteria and a PowerPoint presentation of an ideal crown preparation.

The marks scheme (Table 1) was designed to award a score of one for aspects of an optimum preparation or restoration, two for a clinically acceptable preparation/ restoration (but with one or more errors) and/or restoration and three for a suboptimal preparation/restoration. Hence the minimum overall score for all three restorations that could be awarded was 35 , with the maximum being 105. The view of the assessors with regard to the overall score was as follows: excellent 35-45, good 45-55, some concerns 55-70, serious concerns $>75$; that is, lower scores represented better performance.

The ordinal data was tested for normality using a Shapiro-Wilk test. Statistical differences between sample groups were identified using a non-parametric MannWhitney test at a significance level of 95\%.

\section{RESULTS}

The exercises were carried out during the first three weeks of August 2012, and the models were assessed over two days in mid-September. First, the assessors worked independently, assessing the first ten sets of models and comparing their findings. Following this calibration exercise, a common set of criteria was developed. Each set of models was examined by one examiner, but with a consensus view from both examiners in cases when a grade three (fail) mark was awarded.

A total of 67 FDs completed the assessments, with the total scores ranging from a low of 36 to a high of 87 (Fig. 1), with the mean score being 54.8. FDs who achieved scores that were indicative of over-preparation (in particular) were counselled regarding their performance. Eleven FDs (17.5\%) achieved combined scores 
for all preparations exceeding 70 , this indicating that there were some concerns and five (8\%) achieved scores above 75, indicating serious concerns about operative techniques. The result of a Shapiro-Wilk normality test of the ordinal data obtained in the current investigation is presented in Figure 2. A significant difference in the pattern of data was observed, compared with that expected from a population with a normal distribution ( $\mathrm{p}<0.05$ ),

Regarding the amalgam cavities, the mean score was 8.6, with the maximum (worst) score being 15 and the best being 5 . There were few preparations that were underprepared, with the most common failing being over-preparation in a pulpal direction, either at the pulpo-axial wall or at the floor of the occlusal lock, with the assessors considering that there was a likely pulpal exposure in at least three preparations, with Figure 3 presenting an example. Regarding the amalgam restorations, the mean score was 6.1, where the maximum (worst) score was 12 and the least was 4 .

Regarding the resin composite Class IV restorations, a mean score of 12.0 was achieved, with the maximum (worst) achievable being 24 and the least (best) being 8 . Most common among the problems observed was the lack of a contact point or an incorrectly contoured mesial-incisal angle. While neither of these problems would result in damage to the tooth, it may be considered that either or both could be aesthetically unacceptable to a patient and would be likely to result in a patient's re-attendance. The labial surface of some restorations was found to be concave in a number of cases. Figure 4 presents a composite restoration that achieved a score indicating only minor problems.

Regarding the crown preparations, the range of scores achieved was from 9 to 27 , with a mean score when the metal-ceramic crown preparation was carried out without the aid of a putty matrix of 14.5 , and with the mean score when a putty matrix was used to guide the preparation of 12.4, not statistically different $(p<0.01)$. A particular failing observed was the lack of a chamfer in many preparations - indeed, so often was this observed by the assessors that they were of the opinion that the majority of FDs did not have clear understanding of what a chamfer preparation looked like, nor why it was appropriate to the palatal aspect of the metal-ceramic crown preparation. A small number of crown preparations demonstrated less-than-ideal knowledge of the concept, an example being presented in Figure 5. However, there were a number of preparations that fulfilled the guidelines, an example being presented in Figure 6 .

Students with a score greater than 70 were provided with a brief document summarising their results and with a view to counselling them on their performance.

\section{DISCUSSION}

This was an innovative project, with the authors not being aware of any such audit being carried out previously on recently graduated dentists. The methodology was considered to have performed satisfactorily in so far that it identified a wide range of performance and specific areas for improvement. Only a small number of amendments were considered desirable for the assessment forms, namely, that a clearer distinction be made between gross under-preparation and gross over-preparation, both of which could achieve a maximum score of three units in the present audit. Further work is now indicated to ascertain if this type of standardised assessment has the potential to be used to objectively measure progress with operative skills during the training programme.

As anticipated, there was wide variation in the scores for the preparations and for the resin composite restorations, with the least variation being apparent for the amalgam restorations. Further analysis could be considered desirable, in order to determine whether any factors may have contributed to the FDs performance, with school of graduation, gender and/or performance in previous assessments being possible markers. However, predicting the performance of dental students from admission to dental school through to final year has previously proved difficult, with Rich and co-workers from the University of Otago, New Zealand finding that pre-admission students' scores did not predict performance in the dental programme. ${ }^{5}$ These workers surmised that this may have been as a result of the increasing clinical component as the student progresses, with the relationship between academic record and clinical performance not being clearly defined. ${ }^{6,7}$ Similar difficulties in prediction of the FDs' performance in a clinical exercise may therefore exist. Another useful analysis might be to evaluate performance in the present audit with that of the FDs' national recruitment assessment score, which specifically excludes an assessment of clinical skills.

There were a number of commonly observed operative failings, principal among these being the palatal preparation for a shoulder, when a chamfer preparation was suggested as appropriate; perhaps indicating that a majority of FDs had not carried out a chamfer preparation as undergraduates. This results in over-preparation of the tooth. In this regard, it has been considered by Bottino and colleagues ${ }^{8}$ that the best cervical adaptation for metal crowns was achieved with a chamfer finish line, so it

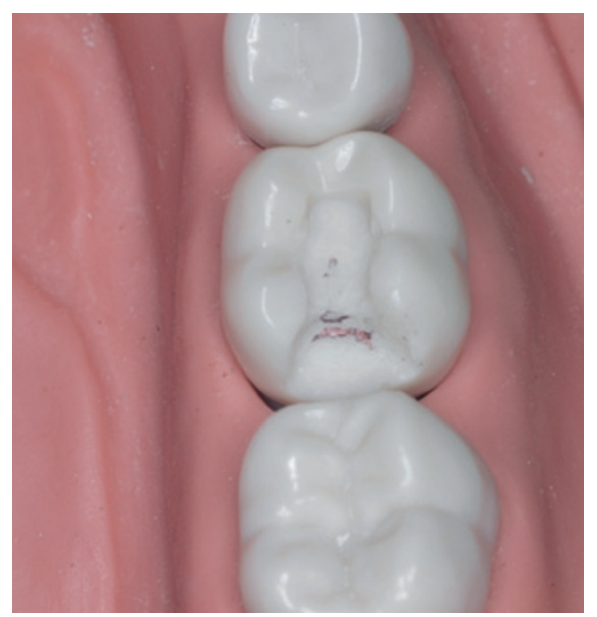

Fig. 3 An example of a potential pulpal exposure in an amalgam preparation

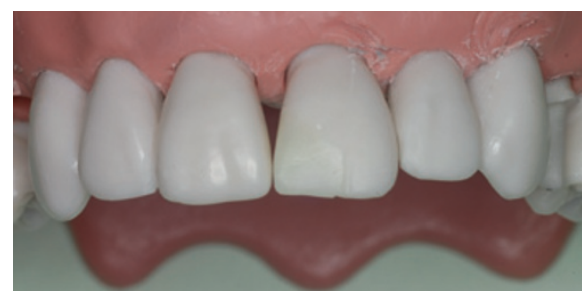

Fig. 4 A resin composite restoration which achieved a good score. Slight ledge at restoration interface at the incisal edge

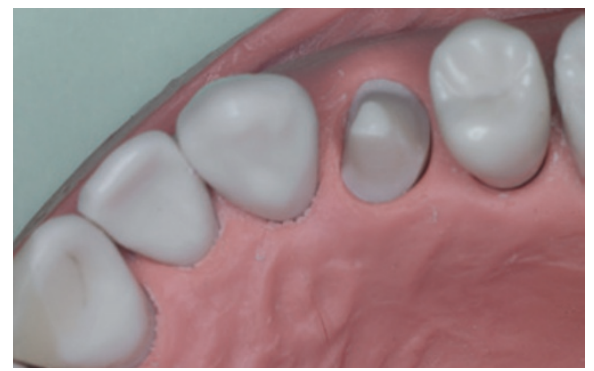

Fig. 5 Crown preparation demonstrated lessthan-ideal knowledge of the concept, with no resistance form, likely pulpal exposure, sharp internal angles and preparation grossly overcut

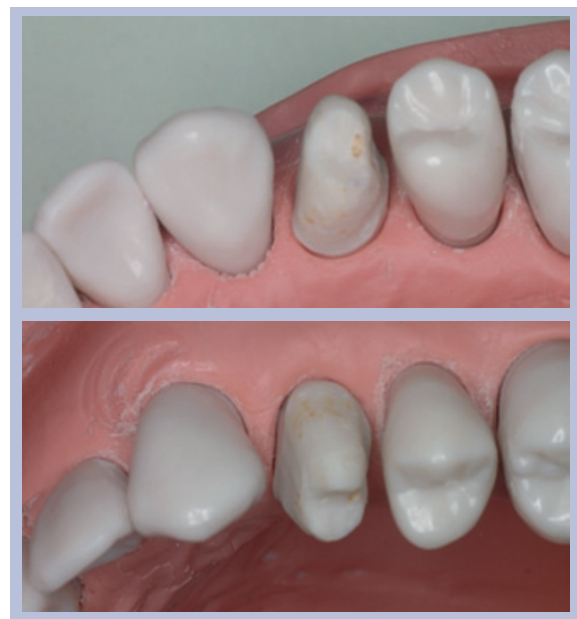

Fig. 6 Crown preparation which fulfiled the majority of the guidelines, although there is a buccal chamfer where there should be a shoulder. However, this represents underrather than over-preparation 
would appear ideal that undergraduates and FDs are familiar with this type of finish. On the other hand, Wostmann and co-workers ${ }^{9}$ have examined marginal discrepancies of metal alloy crowns, based on preparation of 90 volunteer patients' teeth that were intended for extraction, with the results indicating that the marginal designs of the preparations had 'much less influence' on the fit of the castings than they had anticipated.

Over-preparation, rather than underpreparation, was seen as the more usual error. Unfamiliarity with the equipment and surroundings could be considered to contribute to this, however, such difficulties did not prevent circa ten FDs carrying out exemplary preparations and/or restorations. The use of plastic teeth rather than extracted human teeth may have also contributed to over preparation, particularly if FDs were not experienced in cutting plastic teeth. However, it does enable greater standardisation.

The use of a putty matrix did not appear to result in significantly improved crown preparations, although the scores for preparations made while using a matrix were better than those without a matrix. There is a paucity of data on this subject, although Mollersten, in $1989,{ }^{10}$ when examining the precision of freehand and instrumentguided preparations under simulated clinical conditions, found that guided preparations provided better precision than freehand, but did not exclude success by the freehand approach, the latter being similar to the findings of the present work.

In theory, it has been considered that the more parallel the opposing walls of a crown preparation, the greater the retention, ${ }^{11}$ but, conversely, parallel walls also carry the risk of incorporating undercuts into the tooth preparation, ${ }^{12}$ with Mack considering that a minimum taper of 12 degrees was necessary to reduce the risk of incorporating undercuts into the tooth preparation. ${ }^{13}$ In the present study, the convergence angles in the preparation were variable, but this has also been observed when 499 preparations made by dental students in Egypt, Saudi Arabia and Ohio, USA were examined by Ayad and co-workers. ${ }^{11}$ These workers found that the convergence angles differed among the three groups of dental students, with the greatest convergence value $\left(19.8^{\circ}\right)$ being for the bucco-lingual measurements prepared by the Egyptian students and the smallest $\left(14.1^{\circ}\right)$ being the mesio-distal measurements prepared by the Saudi students. The results of the present project indicate that dentists in their first weeks of practice (in other words with similar experience to final year dental students) are little different to the dental students in the study by Ayad et al. ${ }^{11}$

The findings of two other studies may be of relevance. Al-Omari and Al-Wahadni examined a variety of aspects of full crown preparations made by dental students in Jordan on a variety of teeth. ${ }^{14}$ It was found that only $9 \%$ of the prepared teeth achieved the recommended bucco-lingual convergence and 16\% achieved the ideal mesio-distal convergence. The mean occlusal reduction, of two mm, was considered satisfactory but the chamfer finish was found to be wider and heavier than the ideal. Annerstedt and colleagues ${ }^{15}$ examined 127 crown preparations made by dental students in Goteborg University and 351 preparations made by dentists that had been scanned, finding that there was a wide range of convergence angles of the axial walls, especially for the preparations performed by the practitioners. It may be considered therefore, that the performance of the FDs assessed in this study is within the levels of variability, other than in a small number of cases, which has been observed in previous studies of dental students and practitioners.

Finally, the study by Guth and co-workers, ${ }^{16}$ may be considered relevant to the present work. This used an intraoral scanner to evaluate the tooth preparations from 75 general dental practitioners in Germany for zirconia crowns on upper left first molar teeth, which had been carried out in their practices during the normal daily routine. The results indicated difficulties fulfilling the authors' clinical recommendations, with no preparation fulfilling all preparation guidelines. In addition, 30\% of the occlusal reductions were considered insufficient, with inadequate clearance over the mesiobuccal cusp being a particular problem and 31\% of the preparations exhibiting undercuts. As a result, the authors concluded that general dental practitioners seem to have difficulties in fulfilling all the clinical recommendations for the preparation of all-ceramic crowns. It may therefore be suggested that, in the light of the above data, the results presented in the present work may be more typical of general dental practice than was originally envisaged.

\section{CONCLUSIONS}

There was wide variability in the performance of the FDs and the factors influencing this will be the subject of further study. The marking scheme appeared to perform well while auditing the preparations and restorations of FDs from the Oxford and Wessex Deanery, although further refinement of the assessment system may be indicated.

Thanks are due to Dr Cathie Brady (Training Programme Director for Buckinghamshire) for carrying out a pilot to test the methodology used in this project without formal assessment in 2011/2012.

1. The National Health Service (Performers Lists) (England) regulations 2013. Online regulations available at http://www.legislation.gov.uk/ uksi/2013/335/made (accessed February 2014).

2. Committee of Postgraduate Dental Deans and Directors. A curriculum for UK dental foundation programme training. COPDEND. Online curriculum available at http://www.copdend.org/data/ files/Foundation/Dental\%20Foundation\%20 Programme\%20Curriculum.pdf (accessed April 2014).

3. Shillingburg $H$ T, Jacobi $R$, Brackett $S E$. Fundamentals of tooth preparations. Chicago: Quintessence Publishing Co, 1987.

4. Ryge G. Clinical criteria. Int Dent J 1980; 30: 347-357.

5. Rich A M, Ayers K M S, Thomson W M, Sinclair R J, Rohan M J, Seymour G J. Does performance in selection process predict performance as a dental student? Eur J Dent Educ 2012; 16: 27-34.

6. Smithers S, Catano V M, Cunningham D P. What predicts performance in Canadian dental schools? J Dent Educ 2004; 68: 596-613.

7. McManus C, Powis D. Testing medical school selection tests. Med J Aust 2007; 186: 118-119.

8. Bottino M A, Valandro L F, Buso L, Ozcan M. The influence of cervical finish line, internal relief and cement type on the cervical adaptation of metal crowns. Quintessence Int 2007; 38: e425-432.

9. Wostmann B, Biober T, Gouentenoudis M, Balkenhol $M$, Ferger P. Influence of margin design on the fit of high-precious alloy restorations in patients. J Dent 2005; 33: 611-618.

10. Mollersten L. Comparison between guided and freehand preparation. J Prosthet Dent 1989; 62: 130-139.

11. Ayad M F, Maghrabi A A, Rosensteil S F. Assessment of convergence angles of tooth preparations for complete crowns among dental students. J Dent 2005; 33: 633-638.

12. Ohm E, Silness J. the convergence angle in teeth prepared for artificial crowns. J Oral Rehabil 1978; 5: 371-375.

13. Mack P J. A theoretical and clinical investigation into the taper achieved on crown and inlay preparations. J Oral Rehabil 1980; 7: 255-265.

14. Al-Omari W M, Al-Wahadni A M. Convergence angle, occlusal reduction and finish line depth of full-crown preparations made by dental students. Quintessence Int 2004; 35: 287-293.

15. Annerstedt A L, Engstrom U, Hansson A et al. Axial wall convergence of full veneer crown preparations. Acta Odontol Scand 1996; 54: 109-112.

16. Guth J F, Wallbach J, Stimmelmayr M, Gernet W, BNeuer F, Edelhoff D. Computer-aided evaluation of preparations for CAD/CAM-fabricated all-ceramic crowns. Clin Oral Investig 2013; 17: 1389-1395. 